\title{
FAULT LOCATION IN RADIAL DISTRIBUTION NETWORK BASED ON FAULT CURRENT PROFILE AND THE ARTIFICIAL NEURAL NETWORK
}

\author{
MAJID DASHTDAR, MASOUD DASHTDAR \\ Electrical Engineering Department, Bushehr Branch, Islamic Azad University, Bushehr, Iran \\ E-mail: Dashtdar.masoud@gmail.com
}

\begin{abstract}
Electricity distribution systems are subject to a variety of faults such as permanent and transient short circuits due to the extent and multiplicity of equipment. In principle, short circuit fault causes the existing protective equipment to operate and to no electricity the various parts of the distribution network. Rapid and accurate determination of fault location, repair and recovery, it has not prevented the distribution of energy. This will satisfy consumers and prevent the losses of electricity companies. In this paper, the artificial neural network and fault current profiles are used to determine the distance of the fault, determine the type of fault and detect the short circuit. This method provides the information needed to locate the fault by sampling the current before and after the fault occurs from the SCADA system. The effect of connectivity local resistance changes and the effect of load changes on fault location were evaluated. The results show that this method is more accurate than the voltage droop profile variation method in determining the fault distance and short circuit breakdown. If only the net fault current changes profile is used, the effect of the load changes in determining the short-circuit breakdown is much less.
\end{abstract}

Keywords: Electrical distribution network, Fault location, Artificial neural network, Net fault current profile

\section{INTRODUCTION}

Improving the reliability level of distribution networks has attracted the attention of many electrical industry experts. Due to the wide structure and variety of equipment used, electricity distribution networks are susceptible to a variety of faults and are therefore less reliable. The most important causes of fault occurrence in distribution networks are lightning, insulation break, short-circuiting by branches of trees and birds. Many faults are transient in nature and are often resolved without loss of power or at the shortest cutoff time, but persistent faults cause the network to become out of service for a longer time [1].

In distribution networks, physical presence is very difficult to fault find in all locations of the network, and sometimes it is not possible, therefore, to use fault detection methods can be very effective. Detecting a fault location without a clear idea of the type and extent of the fault is difficult and time-consuming. On the other hand, high accuracy in fault location significantly reduces the time needed to repair the distribution network damage [2].

Various information and data are used in fault location methods. Fault location methods can be divided into three categories: traveling wave, impedance, and intelligent algorithms [3].

The traveling wave method requires accurate monitoring on one or both sides of the line to record the reflection of the voltage and current waveforms from the point of fault to the location of the measuring device. With this information, the fault distance to the location of the measuring device can be detected [4-6]. This method is not suitable for lines that have high divisions until the fault occurs location. Because many reflections of the waves reach the measuring device. Also, this method is sensitive to network loose connections which cause the breakage of the waves and is also not cost-effective due to the high cost of the equipment used.

In the impedance method, the voltage and current are first measured at the power station and then by the mathematical equations governing the network structure including the impedance of the lines, the impedance of the load and the impedance of the fault, the fault distance can be determined [7-9]. Due to the tree structure of distribution networks and the use of a recorder at the beginning of the station, the number of candidates for the fault location in this method is high. This method also uses the information of the protection devices on the network to determine the most likely fault location [10]. Changes in fault impedance, power supply impedance and load variations reduce the accuracy of fault location [11].

In intelligent methods, artificial neural network algorithms, fuzzy logic, expert systems, and genetics are commonly used for fault location [12-14]. This method depends on accurate input information so that it can produce accurate and reliable output. In many cases, at low voltage levels, system information is not fully available and it is difficult to obtain an accurate answer under these conditions. If enough information is available, an accurate answer can be obtained in a short time away from human error. In [16-26], smart meter devices and artificial neural network techniques are used to detect the faulted section and fault location in the distribution network.

In this paper, a synthetic method based on artificial neural network and linear changes of net fault current are proposed to accurately determine the location of the fault. In this method, candidates for the fault location are generated for networks having a tree structure. These candidates are ranked by reasoning algorithms to determine the location of the fault more quickly. 


\section{PROPOSED ALGORITHM FOR FAULT LOCATION}

The proposed algorithm for the purpose of fault location consists of three parts: determining the type of fault, determining the fault location and detecting the shortcircuit line.

\subsection{Algorithm to determine the type of fault}

In the proposed method to determine the type of fault, the three-phase current is recorded at the beginning of the station at the time of the fault. The procedure for determining the type of fault is as follows steps.

Step 1: Extract Symmetrical Components of the current by Symmetrical Component Transform Matrix (Equation 1).

$$
\left[\begin{array}{l}
\mathrm{I}_{0} \\
\mathrm{I}_{1} \\
\mathrm{I}_{2}
\end{array}\right]=\frac{1}{3}\left[\begin{array}{ccc}
1 & 1 & 1 \\
1 & \mathrm{a} & \mathrm{a}^{2} \\
1 & \mathrm{a}^{2} & \mathrm{a}
\end{array}\right]\left[\begin{array}{c}
\mathrm{I}_{\mathrm{a}} \\
\mathrm{I}_{\mathrm{b}} \\
\mathrm{I}_{\mathrm{c}}
\end{array}\right], \quad \begin{gathered}
\mathrm{a}=1<120^{\circ} \\
\mathrm{a}^{2}=1<-120^{\circ}
\end{gathered}
$$

Step 2: In order to detect a fault, the amplitudes of the three-phase currents are compared to the nominal current of the network. A fault occurs if one of these ratios exceeds the nominal current value (Equation 2).

$$
\frac{\left|\mathrm{I}_{\mathrm{k}}\right|}{\left|\mathrm{I}_{\text {nominal }}\right|}>1, \mathrm{k}=\mathrm{a}, \mathrm{b}, \mathrm{c}
$$

Step 3: To identify single-phase short-circuit, $1 / 3$ value of the current amplitude of each phase is compared with the phase sequence current amplitude obtained from the first step (Equation 3).

$$
e_{m k}=\left|\frac{1}{3}\right| I_{k}|-| I_{m}||, \quad\left\{\begin{array}{c}
\mathrm{k}=a, b, c \\
m=0,1,2
\end{array}\right.
$$

Single-phase short-circuits when the following conditions are met:

$$
\mathrm{e}_{1 \mathrm{k}} \text { and } \mathrm{e}_{2 \mathrm{k}}<\left|\mathrm{I}_{1}^{0}\right|, \quad\left|\mathrm{I}_{2}\right|<\left|\mathrm{I}_{\mathrm{k}}\right|, \quad\left|\mathrm{I}_{0}\right|>\in(4)
$$

In Equation (4), $\mathrm{I}_{1}{ }^{0}$ is the positive sequence current amplitude before the fault occurs, and $\in$ is a small number due to a computational error, which can ideally be set to zero. To determine the short-circuited phase, the amplitudes of the currents are compared, they showed the greater amplitude of each phase current is short-circuited.

Step 4: In order to detect two-phase short-circuit, the threephase current is compared and the two larger values (in amplitude) are called $\mathrm{I}_{\mathrm{LL} 1}$ and $\mathrm{I}_{\mathrm{LL} 2}$, respectively, and are compared with the sum of the phase sequence current magnitude.

$$
E_{\mathrm{x}}=\left|\mathrm{I}_{\mathrm{LLx}}-\right| \mathrm{I}_{0}+\mathrm{I}_{1}+\mathrm{I}_{2}||, \mathrm{x}=1,2
$$

Two-phase short-circuit when the following conditions are met:

$$
\mathrm{E}_{\mathrm{x}}<\left|\mathrm{I}_{1}{ }^{0}\right|,\left|\mathrm{I}_{0}\right|<\epsilon,\left|\mathrm{I}_{2}\right|>\epsilon
$$

Step 5: Short-circuit, when two-phase to ground the following conditions, are met:

$$
\begin{aligned}
& \| I_{0}|+| I_{2}|<| I_{1}|,| I_{0}|>\epsilon,| I_{2}|<| I_{k} \mid \text { and }\left|I_{j}\right|, \\
& j \neq k=a, b, c
\end{aligned}
$$

To determine the short-circuited phases, the two phases with the highest current amplitude are designated as faulted phases.

Step 6: To determine the short-circuit of three-phases, if the sequence current value is zero and negative is less than $\epsilon$, the type of connection will be three-phases.

$$
\left|\mathrm{I}_{0}\right| \text { and }\left|\mathrm{I}_{2}\right|<\epsilon
$$

\subsection{Algorithm to determine the fault distance}

To illustrate the algorithm for fault location detection and testing of the proposed method, the standard IEEE 34 bus distribution network shown in Figure 1 is considered [15]. The process of fault location identification in the proposed algorithm is designed in three steps.

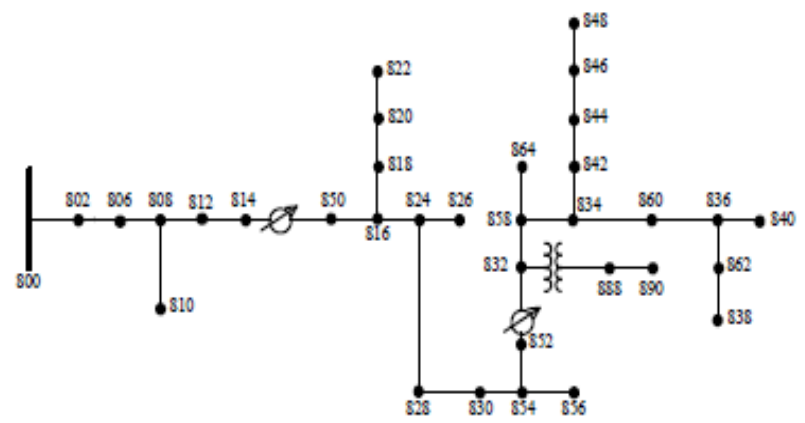

Figure 1. IEEE 34-bus standard network.

In the first step, the database is formed based on the amplitude and angle of the current and the short-circuit phase impedance magnitude, then the database information is used to train the artificial neural network (ANN). In the second step, after detection of the type of fault, the ANN (depending on the type of fault) is selected. In the third step, the distance from the fault location obtained from the ANN is compared with the distance of the distribution network lines from the beginning of the station. As such, the candidate lines for the fault location are identified. 


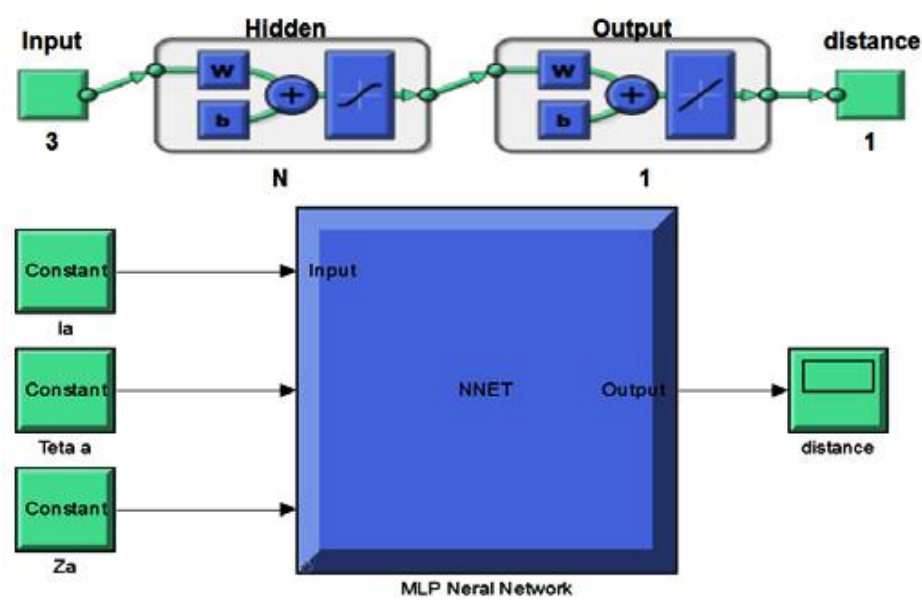

Figure 2. The general structure of the ANN for a single-phase fault to ground (phase a).

Database Generation for ANNs: To form a database, in all of the distribution network lines, are simulated, including short-circuit types, phase to ground, two-phase, two-phase to ground and three-phase. Based on the data recorded in the database and the type of fault, $10 \mathrm{ANN}$ are determined. The method of data acquisition is that each distribution network line is divided into 5 parts and every $20 \%$ of the line length is short-circuit simulated. The fault resistance of 0 to $50 \mathrm{ohms}$ in 10 steps with a step of $5 \mathrm{ohms}$ is considered. By making a short-circuit in each line, the amplitude and the angle of current and the magnitude of the impedance of the phase of the short circuit are recorded at the station first. All short-circuit and data simulation steps are performed by DIgSILEN Power Factory software. At the time of data acquisition, all network loads in their nominal state are considered to form the database.

ANN: After establishing the database and recording the required information, an appropriate $\mathrm{ANN}$ is trained to determine the fault location according to the type of fault and short-circuit phases. For example, for the single-phase short-circuit to the ground, three ANNs are considered for phases a, b and c. Generally, 10 ANNs are created to determine the fault location between the types of shortcircuiting. This is due to increased response speed and reduced computational error by the ANN. The type of ANN used in the proposed algorithm is the Multilayer Perceptrons (MLP) type, MLPs are feed-forward neural networks which consist of several layers of neurons with one layer as output layer and other ones as hidden layers. The number of neurons of output and hidden layers and their transfer functions are related to how the problem is defined. Usually, in technical and engineering problems, MLP neural network with one output and one hidden layer is used. In this kind of problem, linear and Sigmund transfer functions are used for output and hidden layers respectively, the inputs to ANN are the amplitude and angles of current and the impedance magnitude of the short-circuited phases. The target function for this ANN is the fault location. The ANN is trained by the Levenberg Marquardt (LM) algorithm. LM algorithm, a powerful offline batch training method for neural networks, is adapted here for online estimation of power system dynamic behavior. To estimate the parameters of the neural network, the LM algorithm is used as it leads to faster convergence within a few cycles following a large disturbance. It is a mix of steepest descent and GaussNewton method and is generally applied for off-line batch learning. For non-linear estimation, LM outperforms the steepest-descent and other conjugate gradient methods. It performs similar to the steepest-descent method when the gradient of the error surface is small while it performs as the Gauss-Newton method when the gradient is large. Thereby, it avoids any shallow region of the error surface once it is close to the minima. The ANN is selected from the MATLAB software toolbox. The general structure of the ANN for phase-a fault to the ground (fault A-g) is shown in Figure 2.

Where in only one hidden layer is used for the purpose of constructing the MLP neural network, while the neurons number is related to the modifying conditions and cannot be specified precisely. It has to be mentioned here that in a particular problem, the number of neurons in the hidden layer can be determined with try-and-error method. The number of output layer neurons is equal to the number of outputs. Linear type and hyperbolic tangent type transfer function are considered for output and hidden layer neurons, respectively, and Levenberg-Marquardt algorithm for neural network training method. The training result of the neural networks for single-phase fault to the ground is shown in Figure 3.

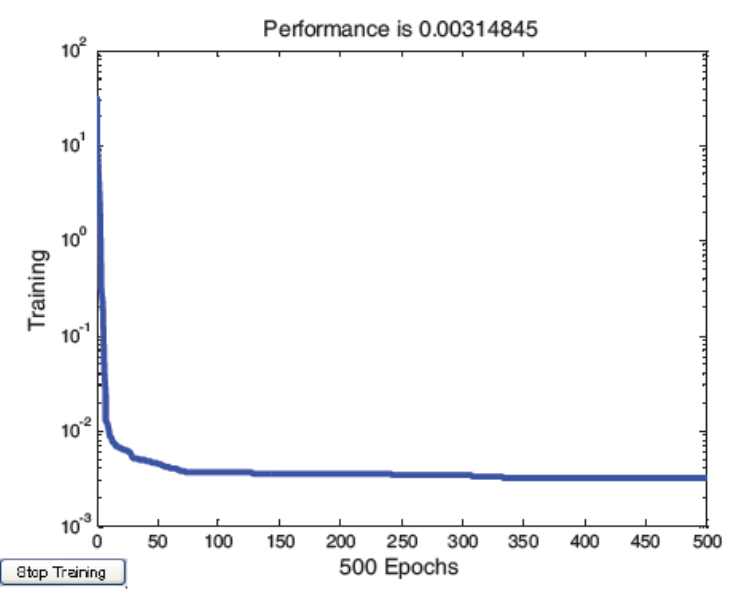

Figure 3. Training result of ANN for single-phase fault to the ground.

The error percentage for the fault location algorithm is obtained from Equation (9). 


$$
\operatorname{error}(\%)=\frac{\left|\mathrm{d}_{\mathrm{F}}-\mathrm{d}_{\mathrm{act}}\right|}{\mathrm{L}} \times 100
$$

In Equation (9), $d_{F}, d_{a c t,}$ and $L$ are the fault location estimated by the ANN and the actual fault location and line length, respectively.

$$
\mathrm{mL}=\frac{\mathrm{d}_{\mathrm{F}}-\mathrm{d}_{\mathrm{P}}}{\mathrm{d}_{\mathrm{Q}}-\mathrm{d}_{\mathrm{P}}}, 0<\mathrm{mL}<1
$$

Define candidate lines for fault: The output of ANN specifies the distance from the location of the fault to the beginning of the station. The fault location obtained is compared with the distance of the distribution network lines from the beginning of the station. Line distance If it establishes the Equation (10) for each line, that line is identified as the candidate for the faulted. This is discussed further in Section 2.3.

In Equation (10), $\mathrm{P}$ and $\mathrm{Q}$ are the beginning and end distances of the station, respectively. $\mathrm{mL}$ The fault distance to per unit is from the beginning of the shortcircuited line.

\subsection{Faulted branch determination}

The proposed algorithm consists of three parts to determine the short-circuited branch. The first part of the database is set based on net fault current phasor. In the second part, based on the data curve fitting method, the net fault current profile for each line is determined. In the third part based on the adaptive algorithm, the net fault current is compared with the information in the database and the short-circuited branch is determined.

Creation of a database for determination of faulted branch: To determine the database for gathering information for the formation of net fault current profile, throughout the distribution network lines of short-circuits types, create $20 \%$ distances along the line with fault resistance from zero to $50 \mathrm{ohms}$. For example, Figure 4 shows the short-circuit of simulated in the sample line.

By doing this short-circuits, the short-circuited phase current and the current before the fault occurs in the faulted phase is recorded. The difference between these currents indicates the net fault current. This current is obtained from Equation (11).

$$
I_{N k t i}=I_{F k t i}-I_{S k}, \quad t=0,5,10, \ldots, 50 \mathrm{Ohm}
$$

In Equation (11),

$\mathrm{I}_{\mathrm{Nkti}}$ : Net fault current,

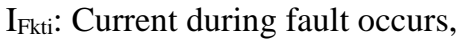

Isk: Current before the fault occurs,

$\mathrm{N}$ : Net fault current index,

F: Short-circuited phase current index during a fault,

$S$ : Information measurement index at the beginning of the station,

$\mathrm{k}$ : Faulted phase index,

t: Fault resistance index,

i: Index of data points,

In order to determine the short-circuited branch, of changes in the imaginary part of the net fault current, is compared to the real part is used.

$$
I_{N k t i}=I_{N k t i}^{(R e)}+i I_{N k t i}^{(I m)}
$$

In Equation (12), $\mathrm{I}_{\mathrm{Nkti}}{ }^{(\mathrm{Im})}$ and $\mathrm{I}_{\mathrm{Nkti}}{ }^{(\mathrm{Re})}$ are the imaginary and real parts of the net fault current, respectively.

Creating net fault current changes profile: From the database, you can obtain the profile of the changes of the net fault current imaginary part relative to the real part. In the distribution network, as most lines, they are shorter in length. Investigations show that a good approximation of $\mathrm{I}_{\mathrm{Nkti}}{ }^{(\mathrm{Im})}$ changes to $\mathrm{I}_{\mathrm{Nkti}}{ }^{(\mathrm{Re})}$ can be assumed to be linear, which can be expressed by Equation (13).

$$
I_{N k t i}^{(I m)}=A^{P Q} \times I_{N k t i}^{(R e)}+B^{P Q}
$$

According to the data in the database, the coefficients of Equation (13) can be obtained from MATLAB fitting curve software or by fitting a line of data to Equation (14).

$$
\begin{gathered}
{\left[\begin{array}{l}
A^{P Q} \\
B^{P Q}
\end{array}\right]=\left[\begin{array}{cc}
\sum_{i=1}^{n} 1 & \sum_{i=1}^{n}\left(I_{N k t i}^{(R e)}\right) \\
\sum_{i=1}^{n}\left(I_{N k t i}^{(R e)}\right) & \sum_{i=1}^{n}\left(I_{N k t i}^{(R e)}\right)^{2}
\end{array}\right] \times} \\
{\left[\begin{array}{c}
\sum_{i=1}^{n}\left(I_{N k t i}^{(I m)}\right) \\
\sum_{i=1}^{n}\left(I_{N k t i}^{(R e)} \times I_{N k t i}^{(I m)}\right)
\end{array}\right]}
\end{gathered}
$$

Data Matching Algorithm: In order to determine the shortcircuited branch in the first step using the ANN the distance of the fault location is determined and according to Equation (10), the candidates of the fault location are identified. The criterion for determining the most probable short-circuit branch is considered based on the minimum of the measured data variations relative to the net fault current profiles of candidate lines. This minimal change can be obtained from geometric relationships.

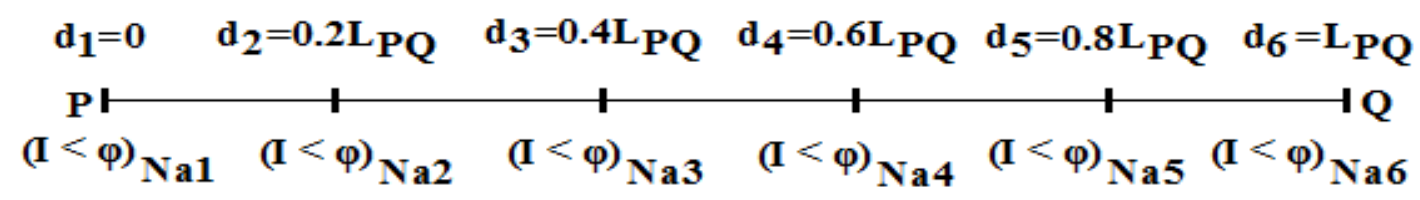

Figure 4. Sample line to form a net fault current profile. 


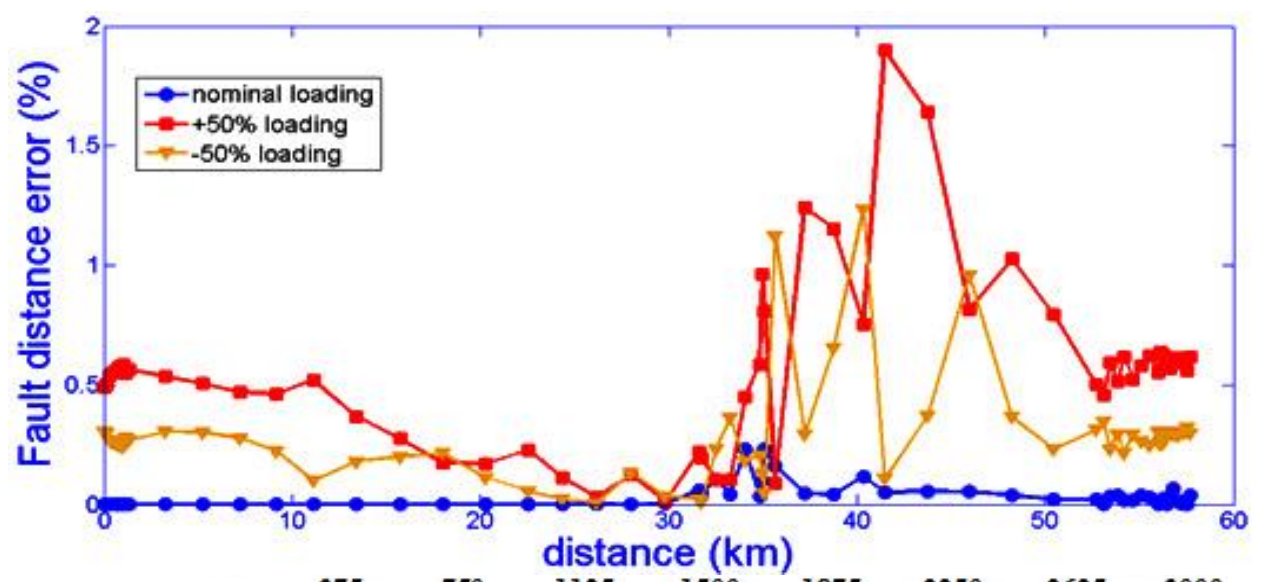

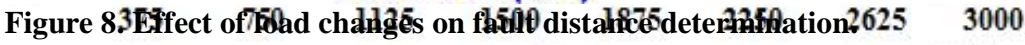

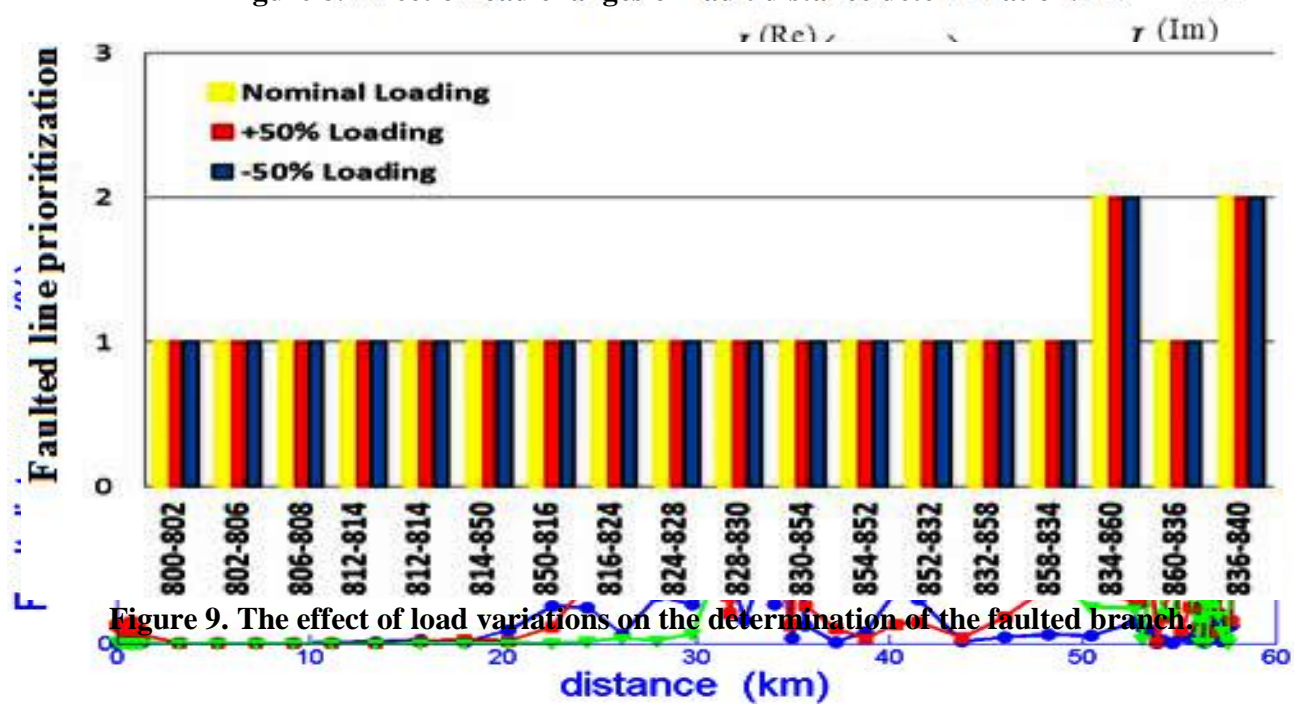

Figure 6. Effect of fault resistance changes on fault distance determination.

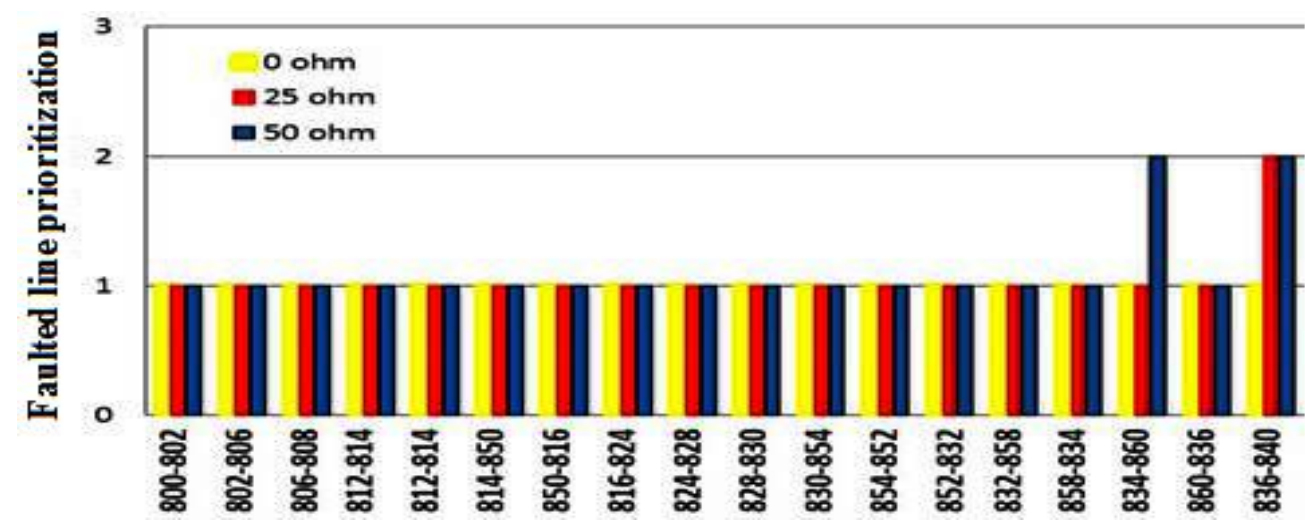

Figure 7. The effect of fault resistance variations on the determination of the faulted branch.

To illustrate this method, we created a single-phase shortcircuit (phase a) sample between two 834-860 buses. Through the distance determination algorithm, two candidate lines (834-842 and 834-860) are selected. By comparing the variations of the measured values with respect to the net fault current profile, each of the candidate lines of fault is determined. These are shown in Figure 5.
According to Figure 5, the value of the point distance measured relative to the net fault current profile can be determined from the geometric relationships of the shortest point distance from the line. This distance can be obtained from Equation (15). 


$$
d_{k}^{P Q}=\frac{\left|A^{P Q} \times I_{N S k t}^{(R e)}-I_{N S k t}^{(I m)}+B^{P Q}\right|}{\sqrt{\left(A^{P Q}\right)^{2}+1}}
$$

According to Figure 5, it can be seen that $d_{2}<d_{1}$. The result shows that the fault occurred in the line between the 834 and 860 buses. Generally, the criterion for determining the faulted branch for short-circuit types is obtained from Equation (16).

$$
\mathrm{e}_{\mathrm{index}}=\sum_{\mathrm{k} \in\{\mathrm{a}, \mathrm{b}, \mathrm{c}\}}\left|\mathrm{d}_{\mathrm{k}}^{\mathrm{PQ}}\right|^{2}
$$

\section{RESULTS OF APPLYING THE PROPOSED ALGORITHM}

In this section, the effects of fault resistance changes and load changes on the proposed algorithm are investigated.

\subsection{The effect of changing fault resistance on fault distance determination}

To prove the accuracy of the proposed method, the results of the effect of fault resistance changes on the fault distance determination at different points of the network, at three levels: zero, 25 and 50 ohms (in single-phase short-circuit) at rated load (constant load changes) in Figure 6 are shown. According to the results, the mean and maximum error in the fault resistance up to $50 \mathrm{ohms}$ are $0.03 \%$ and $0.23 \%$, respectively. The proposed method under much the same conditions is much higher accuracy than the non-linear voltage droop profile, which shows approximately $1.4 \%$ error up to $50 \mathrm{ohms}$ fault resistance [3]. Sudden changes in portions of Figure 6 indicate branches in that area or due to changes in line characteristics. These results indicate the high accuracy of the proposed method in determining the fault distance to the measuring device.

\subsection{The effect of fault resistance change on the determination of the faulted branch}

The results of the study of the effect of fault resistance variations on the algorithm, determination of the faulted branch are shown in Figure 7. In this study, constant load variations are assumed. In unbranched areas and areas characterized by different lines, the short-circuited line is identified in the first step. In areas where the characteristics of identical lines and loads are close to one another, due to the similarity of the fault current profile, the actual short-circuited line will be identified in the next step. The results show that in most cases the proposed algorithm is able to detect the true branch of the shortcircuit in the first step.

\subsection{The effect of changing load on fault distance determination}

In order to demonstrate the ability of the proposed algorithm to detect the fault distance, load changes in three levels: nominal load, 50\% higher and lower than the nominal load in the sample network are considered. In this study the variations of constant fault resistance $(50 \mathrm{ohms})$ and single-phase short-circuit to ground (phase a) are assumed. The results in Figure 8 show that the proposed algorithm is $50 \%$ higher than the nominal load with a mean error of 0.56 and a maximum error of $1.89 \%$ and in $50 \%$ lower than the nominal load, the mean error is $0.28 \%$ and the maximum error is $1.23 \%$. Under the same conditions, determination of fault distance using nonlinear voltage droop profile shows more than $3 \%$ error, the results show the superiority of the proposed method.

\subsection{The effect of the load change on the determination of the faulted branch}

To illustrate the effect of load changes, the conditions mentioned in section 3.3 are considered. The effect of load changes on the algorithm, determination of the faulted branch is shown in Figure 9. The results show that the load changes have little effect on the fault location method using net fault current profile and most of the shortcircuited branches are identified in the first step. This is due to the removal of the effect of load changes on the net fault current profile. Under the same conditions, the proposed method is more accurate than the one presented in [3].

\section{CONCLUSION}

In the combined method of the artificial neural network and fault current profile, the necessary information for fault location is extracted from the SCADA system. This method is able to detect the type of fault, the fault distance to the beginning of the station, and the short-circuited branch with high accuracy (on average less than $1 \%$ error). The results of the study of the effect of fault resistance changes on the proposed method assuming that the load variability is constant, the percentage of error in determining the fault distance to 50 -ohm resistance is $0.03 \%$ average and $0.23 \%$ maximum. Also, the effect of fault resistance variations on the proposed method in determining the short-circuited branch is negligible and in most cases, the faulted branch is identified in the first step. Since with fault resistance up to $50 \mathrm{ohms}$, the error in the voltage droop variations profile method is $1.4 \%$ [3], the comparison results under the same conditions show that the error percentage in order to determine the fault distance in the proposed method is less than half is the error of the voltage droop variations profile method.

In addition, the short-circuited branch due to load changes is often determined in the first step, due to the use of net fault current profile changes where the load changes effect are eliminated. If the fault resistance is assumed to be constant due to load changes, the proposed method has a maximum error of $1.89 \%$ which shows a much lower error compared to the voltage droop profile variations method with more than $3 \%$ error [3]. The proposed method can be considered as an effective method of fault location and is 
economically viable because only one measuring device is used at the beginning of the station.

\section{REFERENCES}

[1] Salim, R.H., Salim, K.C.O. and Bretas, A.S., 2011. Further improvements on impedance-based fault location for power distribution systems. IET Generation, Transmission \& Distribution, 5(4), pp.467-478.

[2] IEEE Std C37. 114-2004, IEEE Guide for Determining Fault Location on AC Transmission and Distribution Lines, 2005, DOI: 10.1109 / IEEESTD.2005.96207.

[3] Mokhlis, H. and Li, H., 2011. Non-linear representation of voltage sag profiles for fault location in distribution networks. International Journal of Electrical Power \& Energy Systems, 33(1), pp.124-130.

[4] Michalik, M., Rebizant, W., Lukowicz, M., Lee, S.J. and Kang, S.H., 2006. High-impedance fault detection in distribution networks with use of wavelet-based algorithm. IEEE Transactions on Power Delivery, 21(4), pp.1793-1802.

[5] Pourahmadi-Nakhli, M. and Safavi, A.A., 2010. Path characteristic frequency-based fault locating in radial distribution systems using wavelets and neural networks. IEEE transactions on power delivery, 26(2), pp.772-781.

[6] Rafinia, A. and Moshtagh, J., 2014. A new approach to fault location in three-phase underground distribution system using combination of wavelet analysis with ANN and FLS. International Journal of Electrical Power \& Energy Systems, 55, pp.261274.

[7] Dashti, R. and Sadeh, J., 2014. Fault section estimation in power distribution network using impedance-based fault distance calculation and frequency spectrum analysis. IET Generation, Transmission \& Distribution, 8(8), pp.1406-1417.

[8] Liao, Y., 2014. A novel method for locating faults on distribution systems. Electric power systems research, 117, pp.21-26.

[9] Herrera-Orozco, A., Mora-Flórez, J. and PérezLondoño, S., 2014. An impedance relation index to predict the fault locator performance considering different load models. Electric power systems research, 107, pp.199-205.

[10] Das, S., Karnik, N., and Santoso, S., 2012. Distribution fault-locating algorithms using current only. IEEE transactions on power delivery, 27(3), pp.1144-1153.

[11] Krishnathevar, R. and Ngu, E.E., 2011. Generalized impedance-based fault location for distribution systems. IEEE transactions on power delivery, 27(1), pp.449-451.

[12] F. Dehghani and H. Nezami, "A new fault location technique on radial distribution systems using artificial neural network," 22nd International Conference and Exhibition on Electricity Distribution, Stockholm, June 10-13, 2013, pp. 1-4.
[13] Chen, W.H., 2010. Fault section estimation using fuzzy matrix-based reasoning methods. IEEE Transactions on Power Delivery, 26(1), pp.205-213.

[14] Leão, F.B., Pereira, R.A. and Mantovani, J.R., 2014. Fast fault section estimation in distribution control centers using adaptive genetic algorithm. International Journal of Electrical Power \& Energy Systems, 63, pp.787-805.

[15] Radial Test Feeders-IEEE Distribution System Analysis Subcommittee [Online]. Available: http://ewh.ieee.org/soc/pes/dsacom/testfeeders.html.

[16] Dashtdar, M., 2018. Fault Location in Distribution Network Based on Fault Current Analysis Using Artificial Neural Network. Mapta Journal of Electrical and Computer Engineering (MJECE), 1(2), pp.18-32.

[17] Dashtdar, M., Dashti, R., and Shaker, H.R., 2018, May. Distribution network fault section identification and fault location using artificial neural network. In 2018 5th International Conference on Electrical and Electronic Engineering (ICEEE) (pp. 273-278). IEEE.

[18] Dashtdar, M. and Dashtdar, M., 2019. Fault Location in the Transmission Network Using a Discrete Wavelet Transform. American Journal of Electrical and Computer Engineering, 3(1), pp.30-37.

[19] Dashtdar, M. and Dashtdar, M., 2019. Fault Location in the Transmission Network Based on the Analysis of the Recorded Current by the Relay Using a Discrete Wavelet Transform. In 2rd International Conference on Electrical Engineering, Mechanical Engineering, Computer Science and Engineering.

[20] Dashtdar, M. and Dashtdar, M., 2019. Fault Location in Distribution Network Based on Phasor Measurement Units (PMU). The Scientific Bulletin of Electrical Engineering Faculty, 19(2), pp.38-43.

[21] Dashtdar, M. and Dashtdar, M., 2019. Detecting the Fault Section in the Distribution Network with Distributed Generators Based on Optimal Placement of Smart Meters. The Scientific Bulletin of Electrical Engineering Faculty, 19(2), pp.28-34.

[22] Dashtdar, M. and Dashtdar, M., 2019. Fault Location in the Transmission Network Based on Extraction of Fault Components Using Wavelet Transform. The Scientific Bulletin of Electrical Engineering Faculty, 19(2), pp.1-9.

[23] Dashtdar, M., Esmailbeag, M. and Najafi, M., 2019. Fault Location in the Transmission Network based on Zero-sequence Current Analysis using Discrete Wavelet Transform and Artificial Neural Network.

[24] Dashtdar, M. and Dashtdar, M., 2019. Voltage Control in Distribution Networks in Presence of Distributed Generators Based on Local and Coordinated Control Structures. The Scientific Bulletin of Electrical Engineering Faculty, 19(2), pp.21-27.

[25] Dashtdar, M., Najafi, M. and Esmaeilbeig, M., 2020. Calculating the locational marginal price and solving optimal power flow problem based on congestion 
management using GA-GSF algorithm. Electrical Engineering, pp.1-18.

[26] Dashtdar, M., Esmaeilbeig, M., Najafi, M. and Bushehri, M.E.N., 2020. Fault Location in the Transmission Network Using Artificial Neural Network. Automatic Control and Computer Sciences, 54(1), pp.39-51. 